Short Communication

\title{
Nano-Pt Skin Coated Carbonized Wood Chips with High Catalytic Activity for Electrocatalytic Oxidation of Methanol
}

\author{
Chunyong Zhang ${ }^{1,2, *}$, Fang Lu ${ }^{2,3}$, Jiehong Cheng ${ }^{2,3, *}$, Hengfei Qin ${ }^{1}$, Binglong Zhu ${ }^{1}$, Quanfa Zhou ${ }^{1,2,3}$ \\ ${ }^{1}$ Jiangsu Key Laboratory of Precious Metal Chemistry and Technology, Jiangsu University of \\ Technology, Changzhou, 213001, China \\ ${ }^{2}$ School of Chemistry and Environmental Engineering, Jiangsu University of Technology, Changzhou, \\ 213001, China \\ ${ }^{3}$ Jiangsu Province Key Laboratory of E-Waste Recycling, Jiangsu University of Technology, \\ Changzhou, 213001, China \\ *E-mail: zhangcy@jsut.edu.cn, cjh@jsut.edu.cn
}

doi: $10.20964 / 2018.03 .62$

Received: 20 November 2017 / Accepted: 15 January 2018 / Published: 5 February 2018

A exquisite structure of Nano-Pt Skin (NPS) with high catalytic activity for electrocatalytic oxidation of methanol was fabricated by an in-situ electrodeposition method. Bio-renewable carbonized wood chips (CWCs) ware acted as the precursor of substrate material for the electro. X-ray diffraction (XRD) pattern and scanning electron microscopy (SEM) indicated that the NPS had a high degree of Pt crystallinity. Electrocatalytic oxidation of methanol showed that there was a significant oxidation peak in the cyclic voltammetry $(\mathrm{CV})$ of NPS/CWCs with a peak current density of $705 \mathrm{~mA} / \mathrm{cm}^{2}$. Compared with CWCs, the impedance of NPS/CWCs was small with fast electron transfer rate and had good stability. The unique structure of Nano-Pt Skin Coated Carbonized Wood Chips can be remarkably attributed to the increased activity for electrocatalytic oxidation of methanol at room temperature.

Keywords: Nano-Pt; Carbonized Wood Chips; Electrocatalytic Oxidation; Carbonized Wood Chips; Electrodeposition.

\section{$\underline{\text { FULL TEXT }}$}

(C) 2018 The Authors. Published by ESG (www.electrochemsci.org). This article is an open access article distributed under the terms and conditions of the Creative Commons Attribution license (http://creativecommons.org/licenses/by/4.0/). 